Polymer Journal, Vol. 39, No. 1, pp. 65-72 (2007)

(C) 2006 The Society of Polymer Science, Japan

\title{
Electrospinning of Cellulose Acetate in Solvent Mixture $N, N$-Dimethylacetamide (DMAc)/Acetone
}

\author{
Haiqing LIU ${ }^{1,2, \dagger}$ and Chunyi TANG ${ }^{1}$ \\ ${ }^{1}$ College of Chemistry and Materials Science, Fujian Normal University, Fuzhou 350007, China \\ ${ }^{2}$ Laboratory of Cellulose and Lignocellulosic Chemistry, Guangzhou Institute of Chemistry, \\ Chinese Academy of Sciences, Guangzhou, 510650, China
}

(Received September 25, 2006; Accepted October 30, 2006; Published December 7, 2006)

\begin{abstract}
Electrospinning of cellulose acetate (CA) was studied in relation to factors of solvent composition, size of spinnerete orifice, viscosity, and molecular weight. It was found that cellulose acetate nanofibers were obtained from solvent mixture $N, N$-dimethylacetamide (DMAc)/acetone with volume ratio of 2:1 and 1:2. Beaded nanofibers were more likely formed from solvent 2:1 DMAc/acetone, whereas bead-free CA nanofibers were produced at lower CA concentration in 1:2 DMAc/acetone. The size of spinnerete orifice showed no significant effect on the mean diameter of CA nanofiber, but small size of spinnerete orifice often resulted in nanofibers with large fiber size distribution. With respect to the effect of molecular weight on electrospinning, nanofibers of CA-398-3 $\left(M_{\mathrm{w}}=3.0 \times 10^{4}\right)$ had wide size distribution of $90-790 \mathrm{~nm}$ with large amounts of big spindle-like beads along fibers. The diameters of nanofibers from CA-398-6 $\left(M_{\mathrm{w}}=3.5 \times 10^{4}\right)$ were in the range of $90-430 \mathrm{~nm}$ with a few conical shape beads on fiber. In the case of CA-398-10 $\left(M_{\mathrm{w}}=4.0 \times 10^{4}\right)$, its nanofiber diameters increased to $90-550 \mathrm{~nm}$ without noticeable bead defects. The water contact angles of nanofibers of CA-398-3, CA-398-6 and CA-398-10 were $81^{\circ}, 50.5^{\circ}$ and $40.4^{\circ}$, respectively, suggesting the orientation of hydrophobic and hydrophilic groups on the very outer fiber surface got changed when CA fiber size is down to nanometer range. The interconnected pore volume of CA nanofibrous membranes is tripled with CA molecular weight increasing from $3.0 \times 10^{4}$ to $4.0 \times 10^{4}$. [doi:10.1295/polymj.PJ2006117]
\end{abstract}

KEY WORDS Electrospinning / Cellulose Acetate / Nanofiber / Water Contact Angle /

Electrospinning technique has been widely used in manufacture of polymer and ceramic nanofiber in recent years. ${ }^{1,2}$ Many researches have shown that nanofiber can be applied in areas of filter material, ${ }^{3}$ scaffold for tissue engineering, ${ }^{4}$ protective clothing, ${ }^{5}$ composite material, ${ }^{6}$ sensor ${ }^{7}$ etc. Among many factors affecting the electrospinning, polymer concentration (viscosity), solution conductivity, surface tension, feeding rate, and electric field have been extensively studied and have shown great impact on the electrospinning process, physicochemical structure and morphology of nanofiber, as summarized in a review article. ${ }^{8}$ Two less defined factors, i.e., solvent and molecular weight of polymer also play an important role in electrospinning. A proper solvent, especially the composition in a mixed solvent often decides the feasibility of electrospinning of a polymer. For instance, chitosan nanofiber was capable of being generated from solvent of concentrated acetic acid $/ \mathrm{H}_{2} \mathrm{O}$ instead of diluted acetic acid aqueous solution. ${ }^{9}$ Molecular weight (MW) of some synthetic polymers showed significant influence on the fiber diameter, morphology and some physical properties like crystallinity and thermal behavior. ${ }^{9-11}$ Lower MW polymer generates finer fibers but shows 'beads on a string' morphology, and the average diameter of the electro- spun fibers increases with increasing polymer molecular weight in general. In this report, cellulose acetate (CA), a derivative of natural polymer cellulose, was applied as starting material to study the effect of solvent composition and MW on electrospinning.

Cellulose acetate (CA) nanofibers and nanofibrous membranes with fiber diameter down to submicron were prepared by means of electrospinning technique in several conventional solvents such as acetone, ${ }^{12}$ acetone/dimethylacetamide (DMAc), ${ }^{13}$ acetone/water. ${ }^{14}$ The CA concentration and the nature of collectors on the electrospinning have been studied carefully. In our previous work, on a simple electrospinning apparatus without equipping a syringe pump, CA nanofiber was not formed from solvent of $2: 1$ (v/v) of DMAc/acetone, we thought the failure to obtain nanofiber from this particular solvent system was caused by the high viscosity, which limited the flowing of CA solution to the needle tip. In this work, a syringe pump was connected to the syringe to control the feeding in electrospinning. Our interest focused on the effect of solvent composition, size of spinnerete orifice, viscosity, and molecular weight on the electrospinning of CA. Theoretically the size of spinnerette orifice causes no effect on the fiber size, since nanofiber is drawn from the droplet of polymer solution

${ }^{\dagger}$ To whom correspondence should be addressed (E-mail: haiqing.liu@gmail.com). 
Table I. Molecular weight and viscosity of cellulose acetates

\begin{tabular}{lcc}
\hline Cellulose acetate & $M_{\mathrm{w}}\left(\times 10^{-4}\right)^{\mathrm{a}}$ & Viscosity $^{(\text {poise })^{\mathrm{b}}}$ \\
\hline CA-398-3 & 3.0 & 11.4 \\
CA-398-6 & 3.5 & 22.8 \\
CA-398-10 & 4.0 & 38.0 \\
CA-398-30 & 5.0 & 114 \\
\hline
\end{tabular}

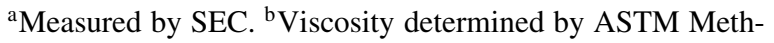
od D 1343 in the solution described as Formula A, ASTM Method D 817.

(Taylor cone) formed in the tip of spinnerette orifice, which is needle or capillary in the case of electrospinning. It is interesting to find out whether or not this concept is correct. CA-398 series specimens with same $\mathrm{DS}_{\text {acetyl }}$ of 2.45 but different molecular weight $\left(3.0-5.0 \times 10^{4}\right)$ were dissolved into solvent $1: 2(\mathrm{v} / \mathrm{v})$ DMAc/acetone to investigate the influence of MW on the electrospinning process, fiber formation and morphology, and wetting properties of CA nanofibrous mats.

\section{EXPERIMENTAL}

\section{Materials}

Cellulose acetates (Table I) were kindly supplied by Eastman, and were used as received. They have same acetyl content of $39.8 \%$ but different molecular weight ranging from $3.0 \times 10^{4}$ to $5.0 \times 10^{4}$.

\section{Electrospinning}

$5 \mathrm{~mL}$ of CA solution in acetone/DMAc mixture was placed in a syringe with a 0.55 (gauge 21) or $0.84 \mathrm{~mm}$ (gauge 18) inner diameter stainless needle. The feeding rate was monitored by a syringe pump (TS2-60, Longer Precision Pump Co. Ltd, Baoding, China) An electrode was clamped on the needle and connected to a power supply (DW-P303-IAC, Tianjin Dongwen High Voltage Plant, China). Grounded counterelectrode was connected to collector aluminum foil. The electrospinning conditions of voltage of $8 \mathrm{kV}$ and tip-to-collector distance of 6 inches were used. The nanofibrous membranes on grounded collector were dried under vacuum at $80^{\circ} \mathrm{C}$ for $10 \mathrm{~h}$ to remove any residual solvents.

\section{Characterization}

Viscosity of CA solution was measured by a rotational viscometer (NDJ-1, Shanghai Precision \& Scientific Instrument Co., LTD, China) at $30^{\circ} \mathrm{C}$. Morphology of the fibrous membrane was observed under scanning electron microscope (International Scientific Instrument, model DS 130). Tensile strength of CA nanofibrous membranes were measured on Twin Column Testing Machine (Lloyd Instruments LTD, UK) at a stretching speed of $2 \mathrm{~mm} / \mathrm{min}$ at $25^{\circ} \mathrm{C}$. The size of testing strips was $100 \times 10 \mathrm{~mm}(\mathrm{~L} \times \mathrm{W})$. Five measurements were conducted to obtain mean values of mechanical strength and Young's modulus. Water contact angle $(\theta)$ and liquid retention capacity (C) were determined by a surface tensiometer (KRÜSS, K14) using a method previously reported..$^{15}$ The contact angle of the membranes can be calculated as:

$$
\theta=\cos ^{-1}\left(F_{\mathrm{w}} / p \gamma\right)
$$

where $F_{\mathrm{w}}, p, \gamma$ are fabric wetting force, fabric-liquid perimeter and liquid surface tension.

Vertical liquid retention capacity $\left(C_{\mathrm{v}}, \mathrm{mg} / \mathrm{mg}\right)$ of a fabric was determined by hanging a fabric strip on a microbalance with only its lower edge in contact with a liquid. The balance reading after separation indicated the amount of liquid retained by the fabric $\left(W_{\mathrm{t}}\right)$.

$$
C_{\mathrm{v}}=W_{\mathrm{t}} / W_{\mathrm{d}}
$$

\section{RESULTS AND DISCUSSION}

CA-398-6 solutions with three concentrations of $15 \%, 20 \%$, and $25 \mathrm{wt} \%$ in 2:1 DMAc/acetone were electrospun. From $15 \mathrm{wt} \%$ solution, CA solution droplets instead of nanofibers were sprayed onto collector (not shown). This phenomenon is the same as the observation found in our previous work. ${ }^{13}$ Nanofibers with mean diameter of $120 \mathrm{~nm}$ started to form when CA concentration was raised to $20 \%$, although dense big beads were decorated along the nanofibers (Figure 1-DA21CA20). As CA concentration was further increased to $25 \%$, bead-free round nanofibers with diameter range of $150-855 \mathrm{~nm}$ but the most frequent fiber diameter of $345 \mathrm{~nm}$ were obtained (Figure 1-DA21CA25). Therefore, with the help of a syringe pump to control the feeding, nanofiber is able to be generated in 2:1 DMAc/acetone although the CA solution in this solvent shows very high viscosity, that is, 116 and 29 poise for $25 \%$ and $20 \%$ CA solutions, respectively, as listed in Table II. In our previous work, we had claimed that solvent with composition of 2:1 DMAc/acetone is not a proper solvent for the electropinning of CA due to its high surface tension. ${ }^{13}$ However, according to our present findings, high viscosity rather than surface tension should be the key factor contributing to the previous failure of electrospinning of CA in this solvent system, since high viscosity limits the flowability of CA solution given that no external forces is provided to push the CA solution to the tip.

The SEM images of CA-398-6 nanofiber from solvent composition of 1:2 DMAc/acetone were presented in Figure 2. Beads only were observed in the electrospinning of $10 \% \mathrm{CA}$ solution (Figure 2- 


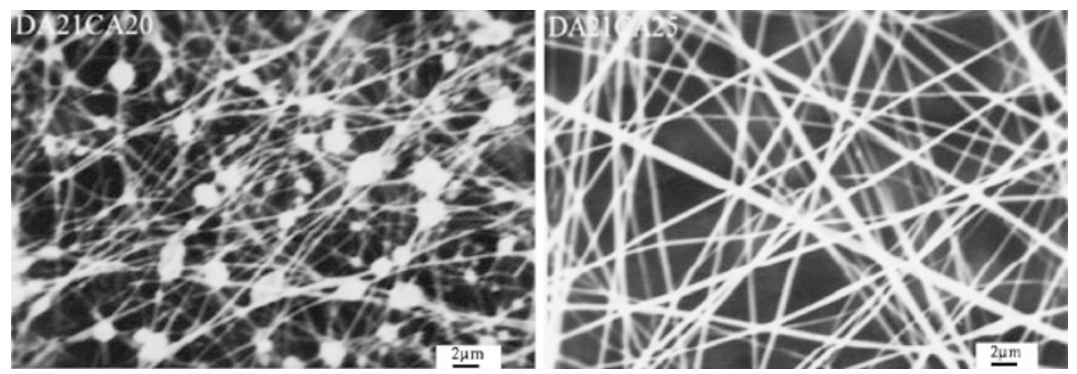

Figure 1. Effect of CA concentration on CA nanofibers from solvent 2:1 DMAc/acetone.

Table II. Viscosity, surface tension and fiber formation of CA in DMAc/acetone

\begin{tabular}{lcccccc}
\hline Solution & $\begin{array}{c}\text { Ratio of } \\
\text { DMAc/acetone } \\
(\mathrm{v} / \mathrm{v})\end{array}$ & $\begin{array}{c}\text { Conc. of CA } \\
(\mathrm{wt} \%)\end{array}$ & $\eta$ (poise) & $\begin{array}{c}\gamma \\
(\text { dyne/cm) }\end{array}$ & Fiber formation & $\begin{array}{c}\text { Diameter of } \\
\text { most } \\
\text { frequent } \\
\text { fibers }(\mathrm{nm})\end{array}$ \\
\hline DA21CA25 & $2: 1$ & 25 & 116 & 30.4 & Good fiber & 345 \\
DA21CA20 & $2: 1$ & 20 & 29.0 & 30.5 & Fiber and beads & 120 \\
DA21CA15 & $2: 1$ & 15 & 13.5 & 30.4 & Beads & - \\
DA12CA25 & $1: 2$ & 25 & 42.0 & 26.5 & Good fiber & 315,1067 \\
DA12CA20 & $1: 2$ & 20 & 15.2 & 26.2 & Good fiber & 483 \\
DA12CA17 & $1: 2$ & 17 & 7.8 & 26.0 & Fiber and beads & 256 \\
DA12CA15 & $1: 2$ & 15 & 3.6 & 26.3 & Fiber and beads & 202 \\
DA12CA12.5 & $1: 2$ & 12.5 & 2.3 & 26.8 & Fiber and beads & 105 \\
DA12CA10 & $1: 2$ & 10 & 1.1 & 26.5 & Beads & - \\
\hline
\end{tabular}

DA12CA10). With CA concentration stepwisely raised to 25\%, dense beads with fiber tail (Figure 2DA12CA12.5), less beads on fiber (Figure 2-DA12CA15, -DA12CA17) and bead-free fiber (Figure 2DA12CA20, -DA12CA25) morphology were produced. It is obvious that the amount of beads formed in the electrospinning of CA is a function of CA concentration or solution viscosity. The higher the CA concentration (or solution viscosity), the fewer beads on fiber is formed. The polydispersity of nanofiber diameter was observed in all CA concentration tested. Fiber diameter of the most frequent nanofibers increased with the increasing of CA concentration or solution viscosity (Table II). Especially, fibers with diameter as large as $c a .1000 \mathrm{~nm}$ were observed when CA concentration was $25 \%$ (Figure 2-DA12CA25). A cross-comparison between DA21CA20 and DA12CA20 showed that 'beads-on-a-string' morphology of DA21CA20 (Figure 1-DA21CA20) in contrast to bead-free fiber of DA12CA20 (Figure 2), though they had same CA concentration and DA21CA20 even had higher viscosity. In this case, the formation of beads (Figure 1DA21CA20) may result from higher surface tension of DA21CA20 than that of DA12CA20 (Table II). In electrospinning it has been well understood that a charged polymer jet is ejected from the Taylor cone by electrostatic force once it overcomes the surface tension. In the course of the jet's traveling to the collector, jet breaks up and retracts into beads if it can not withstand the surface tension and the electrostatic force. ${ }^{16}$

The fiber morphology transition from spherical bead, to elongated bead, and to nanofiber is a function of solution viscosity as suggested by the morphology change in Figure 2, where processing parameters such as solvent system, applied voltage, feeding rate, tip-tocollector distance were kept constant. Therefore, such a morphology change must be caused by parameters of the solution system rather than that of processing. In a polymer solution with a particular solvent composition like 2:1 and 1:2 DMAc/acetone, its viscosity is a function of polymer concentration, whereas its surface tension keeps constant with polymer concentration (Table II). With the increasing of CA concentration in solution, the physical interaction among solvated CA chains changes from isolated(diluted solution) to contacted (semi-diluted solution), and to extensively entangled (concentrated solution). Therefore, the interaction of CA chains in solution are the fundamental factor affecting the electrospinning process and the fiber morphology. It has been reported that a critical chain entanglement concentration $(\mathrm{Ce})$ in the spinning solution should be reached for the fiber formation. Otherwise, electrospraying often takes place in that fluid jet breaks up into small droplets. ${ }^{16,17} \mathrm{In}$ analyzing the electrospinning of $\mathrm{CA}$ in $2: 1$ and 1:2 

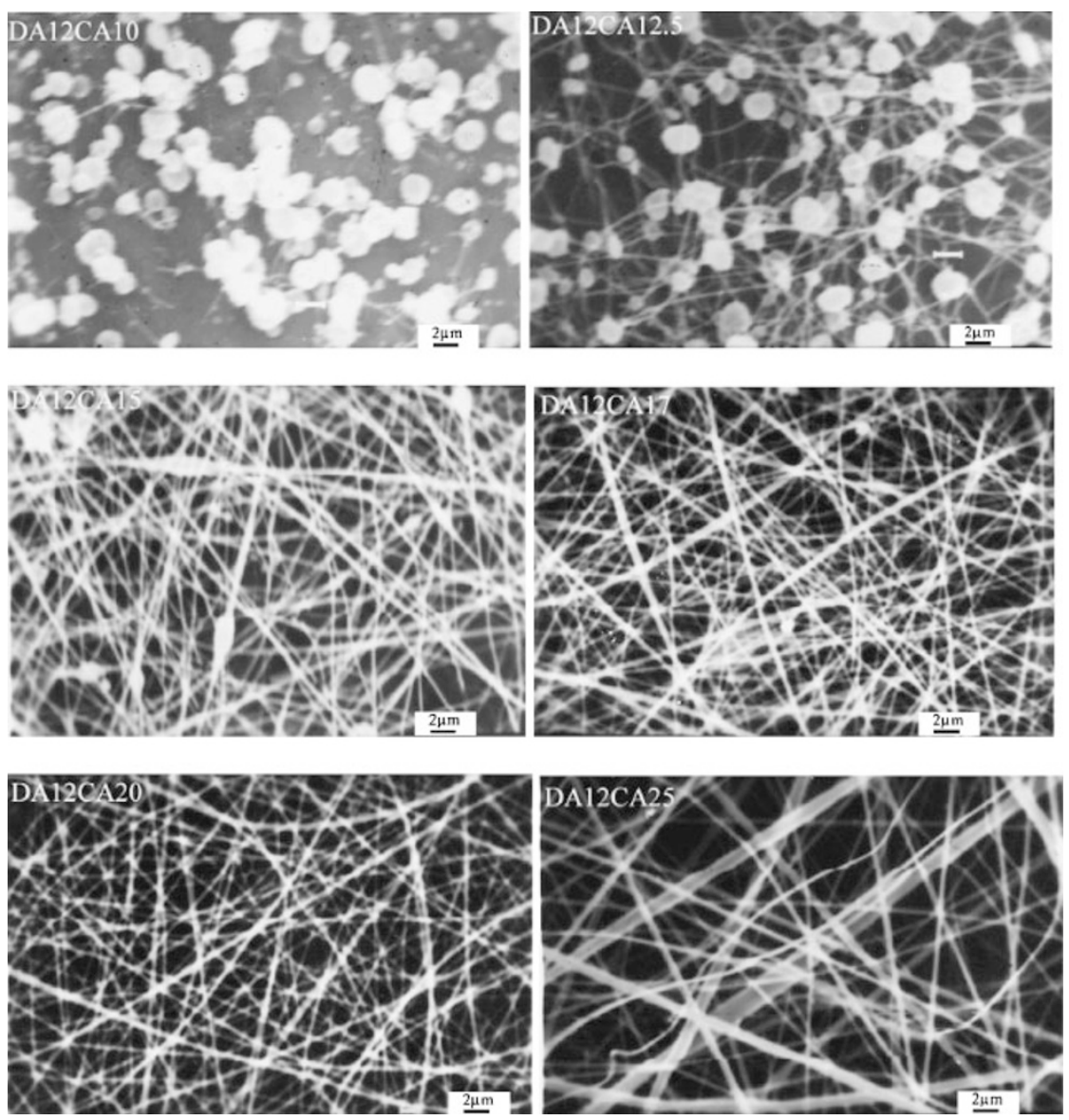

Figure 2. SEM micrographs of CA nanofibers from solvent 1:2 DMAc/acetone.

DMAc/acetone, we found that the critical CA concentrations to form nanofiber are around $20 \%$ and $12.5 \%$ for the former and the latter mixed solvent, respectively. Therefore, CA nanofiber can be formed at much lower CA concentration in solvent system containing more component acetone. The polymer-solvent interaction, another important affecting factor from solution system, is possible contributed to the Ce difference between DA21 and DA12 systems. The strong hydrogen-bonding interaction between CA and DMAc slow down the evaporation of DMAc molecules from the CA jets in the short travel distance from needle tip to the collector. As a result, jet is still wet when it reaches the collector, and solution on the collector tends to retract into spherical bead to make its surface area minimum due to surface tension. We had found that no fiber was formed when DMAc only was applied as solvent for CA. ${ }^{13}$ As the absolute amount of DMAc in the CA jets decreased in DA21CA25, bead-free fibers of DA21CA25 were still produced (Figure 1-DA21CA25).

The SEM images of CA-398-6 fibers generated from 1:2 DMAc/acetone through using 0.55 and $0.84 \mathrm{~mm}$ inner diameter needles were illustrated in Figure 3. For the two CA concentrations, i.e., 20\% and $25 \%$, it is not surprisingly found that the mean fiber diameter of most frequent fibers from $0.55 \mathrm{~mm}$ needle is similar to that from $0.84 \mathrm{~mm}$. This is due to that in electrospinning technique polymer jet is drawn from the Taylor cone suspended at the needle tip instead of from the needle directly. However, fibers from $0.55 \mathrm{~mm}$ needle showed broader fiber size distribution as some fibers (indicated by the arrows) with noticeably larger diameter than the others are present (Figure 3-DA21CA20-0.55, -DA21CA25$0.55)$. In contrast, fiber size is relatively uniform for fibers from $0.84 \mathrm{~mm}$ needle (Figure 3-DA21CA200.84 , -DA21CA25-0.84). This should be closely associated with the different feeding rate caused by the difference of needle size. The feeding rate is a little bit higher in the small needle than in the big one, as the feeding rate monitored by the syringe pump is set. Higher feeding rate often results in large fiber diameters. ${ }^{18}$

A typical stress-strain diagram of CA-398-6 nanofibrous nonwoven (DA21CA25) was shown in Figure 4. All strips tested were tore apart upon elongation. Its strain is as small as $c a .0 .008 \%$. The pretty low strain of CA nanofibrous nonwoven is caused by its semirigid backbone structure. Its stress and Young's modulus at yield point $\mathrm{A}$ are $1.3 \pm 0.2 \mathrm{MPa}$ and $180 \pm 15$ $\mathrm{MPa}$, respectively. The CA nanofibrous nonwoven is 

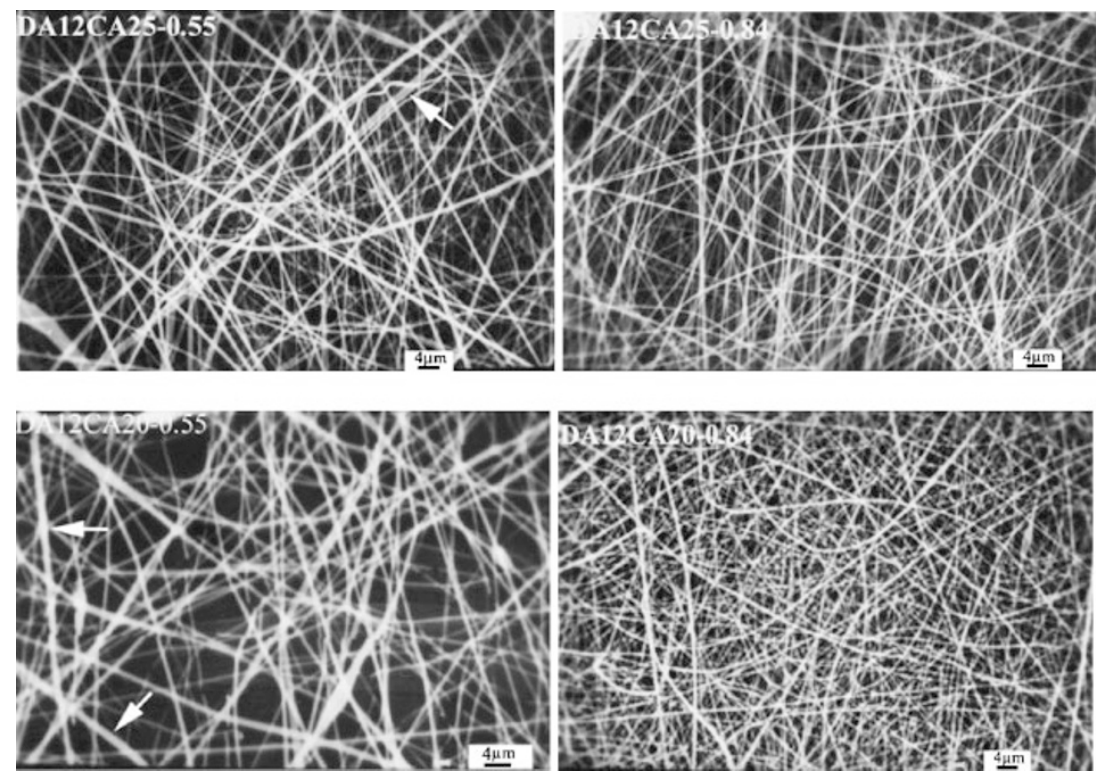

Figure 3. Effect of needle size on the fiber size and morphology.

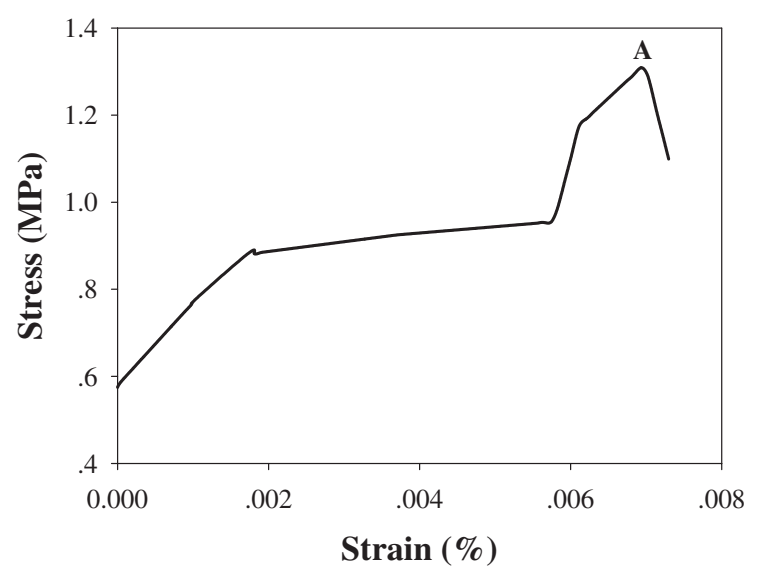

Figure 4. Strain-stress relationship of DA21CA25 nanofibrous membrane.

composed of very short CA nanofibers with length up to several centimeters at most, and fibers are loosely packed together without any chemical crosslinking point among fibers. As a consequence, its tensile strength and Young's modulus are low.

In electrospinning, it has been suggested that polymer molecular weight should be above the entangle molecular weight in order to generate fiber. ${ }^{16}$ In solvent 1:2 (v/v) DMAc/acetone, CA-398-3, -6, -10 with molecular weight in range of 3.0-4.0 $\times 10^{4}$ at a concentration of $15 \mathrm{wt} \%$ were successfully electrospun into nanofibers, indicating CA-398-3 with molecular weight of $3.0 \times 10^{4}$ are above the entangle molecular weight. No fiber except droplets was produced from electrospinning of $15 \mathrm{wt} \%$ CA-398-30 solution. Additionally, $10 \mathrm{wt} \%$ CA-398-30 solution, which has lower viscosity and easy flow ability, did not generate fiber as well, suggesting that the failure to generate nanofiber from CA-398-30 solution may be attributed to its high molecular weight, which may result in poor stretching of molecular chain due to high self-entanglement. During electrospinning, no jet of CA-39830 solution was observed under electrical potential. However, jets of CA-398-3, -6, -10 solutions were formed, and they were splitted and splayed into minijets due to bending instability. ${ }^{17}$ It has been reported that this splitting and splaying of viscoelastic jet has shown to depend on polymer molecular weight. And splaying may become more difficult at high molecular weights since the critical voltage needed for the ejection of the jet from the Taylor's cone is proportional to polymer $M_{\mathrm{w}} \cdot{ }^{17}$

SEM micrographs of CA-398 nanofibers and fiber size distribution were shown in Figure 5. The fiber sizes of CA-398-3 varied widely in the range of 90$790 \mathrm{~nm}$, with $c a .70$ percent of fibers having diameters less than $270 \mathrm{~nm}$. Many large elongated spindle-like beads were observed along CA-398-3 fibers (Figure $5 \mathrm{~A}$ ), indicating the resistance of the jet to extensional flow in the process of electrical potential driven drawing. ${ }^{17}$ As CA $M_{\mathrm{w}}$ increased to $3.5 \times 10^{4}$ for CA-3986 , much more uniform nanofibers of $90-430 \mathrm{~nm}$ in diameters, with much less conical shape beads along fibers were produced (Figure 5B). Nearly 50 percent fibers are $250 \mathrm{~nm}$ in diameter. As to CA-398-10 $\left(M_{\mathrm{w}}=4.0 \times 10^{4}\right)$, its nanofiber diameters increased to $90-550 \mathrm{~nm}$ but without bead defects (Figure 5C). Therefore, CA fiber size distributions are strongly related to the molecular weight of CA, i.e., the lower molecular weight of cellulose acetate, the larger fiber size distribution and the more bead defects. This phenomena is in accordance with the general rule that low molecular weight polymer tend to form beads or bead- 

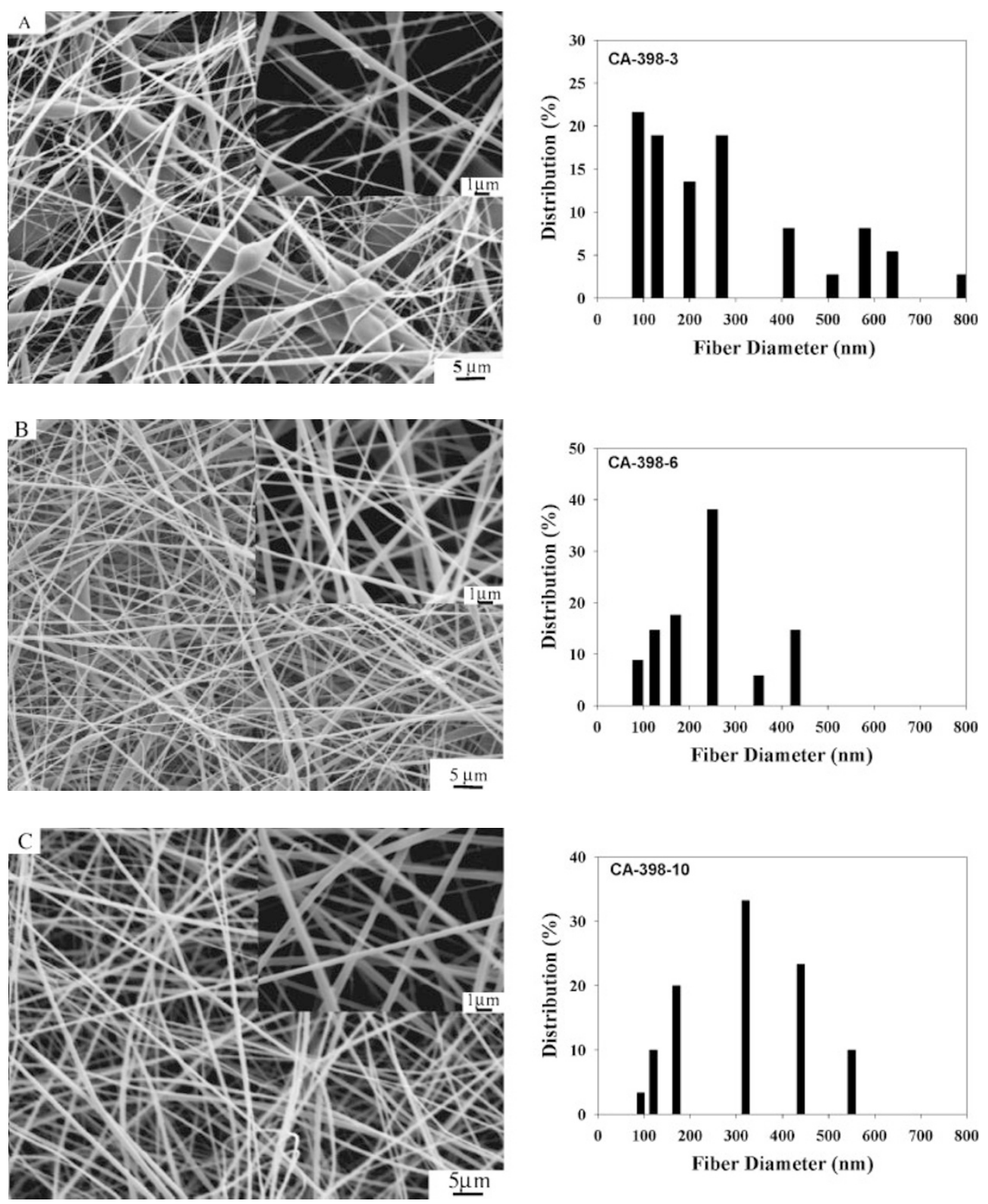

Figure 5. SEM micrographs of CA-398-3 (A), CA-398-6 (B), and CA-398-10 (C) nanofibrous mats. Insets are images of larger magnification; and fiber size distribution of corresponding nanofibrous membranes.

on-string fibers and high molecular weight polymers give fibers with larger average diameter with less defects. ${ }^{11,19}$ It has been reported that polymer molecular weight has a significant effect on the rheological and electrical properties such as viscosity, surface tension, conductivity and dielectric strength of polymer solution. ${ }^{9}$ At the same polymer concentration of $15 \%$, the solution viscosities of CA-398 series increased with molecular weight (Table III). This resulted in significant morphological changes of CA nanofibers from spindle-like beaded fiber with broad fiber size distribution to uniform fiber with narrow fiber size distribution.

The effect of cellulose acetate molecular weight on water contact angle, liquid retention and pore structure of fibrous membranes was shown in Figures 6
Table III. Electrospinning of CA-398 series in 1:2(v/v) DMAc/acetone

\begin{tabular}{lccc}
\hline Sample & Conc (wt \%) & Fiber formation & $\begin{array}{c}\text { Mean fiber } \\
\text { diameter }(\mathrm{nm})\end{array}$ \\
\hline CA-398-3 & 15 & Yes & $275 \pm 195$ \\
CA-398-6 & 15 & Yes & $241 \pm 111$ \\
CA-398-10 & 15 & Yes & $287 \pm 165$ \\
CA-398-30 & 15,10 & No & - \\
\hline
\end{tabular}

and 7. The water contact angle of CA-398-3 nanofibrous membranes was $81^{\circ}$, which is in good agreement with the hydrophobic nature of cellulose acetate. Surprisingly, the water contact angles of CA-398-10 nanofibrous membranes sharply decreased to $40.4^{\circ}$ with CA $M_{\mathrm{w}}$ increased to $4.0 \times 10^{4}$ (Figure 6). How- 


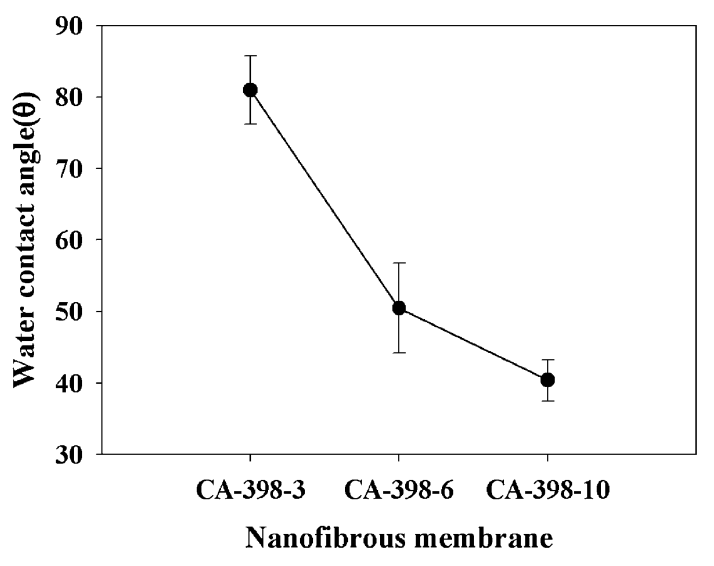

Figure 6. Water contact angle $(\theta)$ of CA-398 nanofibrous membranes.

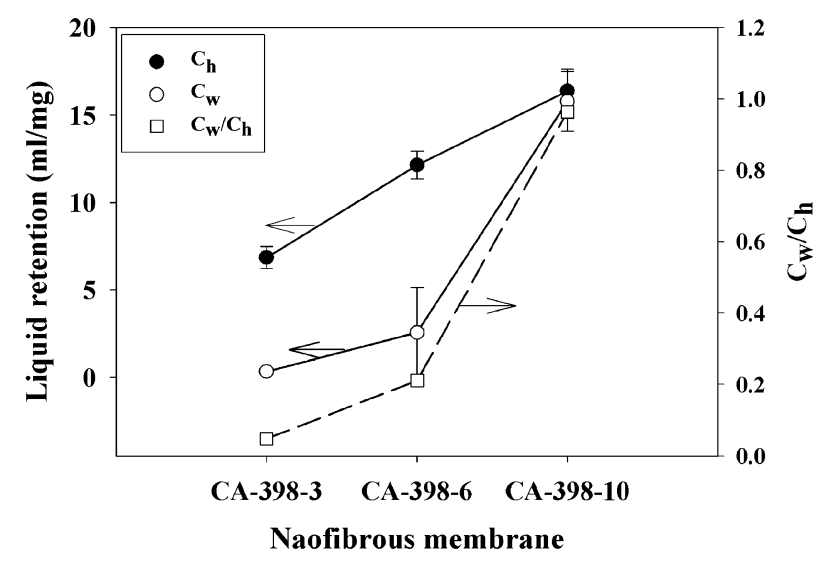

Figure 7. Hexadecane $\left(C_{\mathrm{h}}\right)$ and water retention capacity $\left(C_{\mathrm{w}}\right)$, and $C_{\mathrm{w}} / C_{\mathrm{h}}$ of CA-398 nanofibrous membranes.

ever, this should not be regarded that the wetting property of CA nanofibers can be changed from hydrophobic to hydrophilic with increasing of molecular weight. This alteration should result from the conformational differences in polymer chains on the very fine fiber surfaces, in other words, from the orientation of the hydrophilic and hydrophobic groups in the surface of fiber when it is down to several hundreds nanometers in diameter, since wetting is determined by chemical compositions at the very top surface layer of the fibers. ${ }^{13}$ Though all three CA-398 fibers have average diameter down to $300 \mathrm{~nm}$ (Table III), CA398-3 nanofibrous membranes have large amount of spindle-like beads on fibers which are larger than $5 \mu \mathrm{m}$ in diameter (Figure 5A), CA-398-6 membranes possess fewer and smaller beads along fibers (Figure 5B), and CA-398-10 membranes are composed of uniform and smooth nanofibers without beads. Therefore, in addition to the average fiber size, the amount and size of the spindle-like beads along fibers may also play a significant role in deciding the hydrophobicity of CA nanofibers. We did find that the water contact angle of CA nanofibrous membrane containing fibers with diameter of over 1 micrometer is $75.4 \pm 7^{\circ}$, while that of CA nanofibrous membrane containing fibers with relatively uniform diameter of $c a .450 \mathrm{~nm}$ is $48.8 \pm 8.6^{\circ}$, suggesting the fiber size, when it is down to $500 \mathrm{~nm}$, may alter CA fiber from hydrophobic to hydrophilic. ${ }^{13}$

During electrospinning, fibers randomly deposit on the grounded collector and form 3D nonwoven fiber mats with submicron pores. ${ }^{20}$ Since hexadecane is a total wetting liquid, it can move in the inter-fiber pores by means of capillary wicking when the lower edge of vertically held specimen contact liquid hexadecane. For vertical hexadecane retention capacity $C_{\mathrm{h}}$, it only shows liquid retention in the interconnected pores within the nanofibrous membrane. Therefore, the $C_{\mathrm{h}}$ value serves the indicator of interconnected pore volume of nanofibrous membranes. $C_{\mathrm{h}}$ value increased with CA molecular weight. $C_{\mathrm{h}}$ of CA-398-10 membranes is almost tripled than that of CA-398-3 (Figure 7), suggesting the inter-connected pore volume of CA-398-10 membrane increased significantly. The morphology and volume of pores formed by the fiber packing are strongly dependent on the fiber morphology and size. ${ }^{13}$ The packing of uniform and smooth fibers from CA-398-10 certainly can generate higher volume of pores than that of CA-398-3 fibers with 'beads-on-string' morphology and high fiber size distribution (Figure 5).

Vertical water retention capacity $C_{\mathrm{w}}$ of CA-398-3 was $0.33 \mu \mathrm{L} / \mathrm{mg}$ because high surface tension of water prohibits water from wicking in the interconnected pores in the hydrophobic fibrous membrane. A dramatic $C_{\mathrm{w}}$ increase from $2.6 \mu \mathrm{L} / \mathrm{mg}$ for CA-398-6 to $15.8 \mu \mathrm{L} / \mathrm{mg}$ was observed for CA-398-10 (Figure 7), showing water can wet CA-398-10 nanofibrous membrane and fill the interconnected pores through capillary wicking. The $C_{\mathrm{w}} / C_{\mathrm{h}}$ value for CA-398-10 membrane is almost equal to 1 , suggesting that fiber does not swell under the influence of water. ${ }^{21}$

\section{CONCLUSION}

Critical chain entanglement concentration $\left(C_{\mathrm{e}}\right)$ for the electrospinning of cellulose acetate with $M_{\mathrm{w}}$ of $4.0 \times 10^{4}$ was found to be $20 \%$ and $12.5 \mathrm{wt} \%$ in solvent 2:1 and 1:2 (v/v) DMAc/acetone, respectively. Needle size showed no effect on the fiber diameter, but small size needle often generated CA nanofibers with broad fiber size distribution. The tensile strength and Young's modulus of CA nanofibrous membranes were $1.3 \pm 0.2 \mathrm{MPa}$ and $180 \pm 15 \mathrm{MPa}$, respectively. Electrospinning of cellulose acetate with $M_{\mathrm{w}}$ in the range of 3.0-4.0 $\times 10^{4}$ generated nanofibers and 3D nonwoven nanofibrous mats. Although all three CAs produced nanofibers with mean diameter less than 
$265 \mathrm{~nm}$, nanofibers from low MW CA had large amount of spindle-like beads on fibers, and broad fiber size distribution; nanofibers from high MW CA showed uniform and smooth fiber structure without defects. CA-398-10 fibrous membrane displayed hydrophilic surface property, whereas CA-398-3 nanofibrous mats had characteristic hydrophobic surface possibly due to large amount of spindle-like beads in the membrane structure. The bead-on-string fiber morphology had a significant effect on fiber packing and led to low porosity of fibrous membrane, while membrane from CA-398-10 uniform and smooth fibers had larger interconnected pore volume.

Acknowledgment. This work is partly supported by the Key Project of Natural Science Foundation of Fujian Province (Grant No. 2006J0011).

\section{REFERENCES}

1. D. Li and Y. N. Xia, Adv. Mater., 16, 1151 (2004).

2. W. Sigmund, J. Yuh, H. Park, V. Maneeratana, G. Pyrgiotakis, A. Daga, J. Taylor, and J. C. Nino, J. Am. Ceram. Soc., 89, 395 (2006).

3. C. Shin, G. G. Chase, and D. H. Reneker, Colloid Surf., A, 262, 211 (2005).

4. W. J. Li, C. T. Laurencin, E. J. Caterson, R. S. Tuan, and F. K. Ko, J. Biomed. Mater. Res., 60, 613 (2002).

5. P. Gibson, H. Schreuder-Gibson, and D. Rivin, Colloid Surf., A, 187, 469 (2001).
6. M. M. Bergshoef and G. J. Vancso, Adv. Mater., 11, 1362 (1999).

7. X. Y. Wang, C. Drew, S. H. Lee, K. J. Senecal, J. Kumar, and L. A. Sarnuelson, Nano Lett., 2, 173 (2002).

8. Z. M. Huang, Y. Z. Zhang, M. Kotaki, and S. Ramakrishna, Compos. Sci. Technol., 63, 2223 (2003).

9. X. Y. Geng, O. H. Kwon, and J. H. Jang, Biomaterials, 26, 5427 (2005).

10. C. L. Casper, J. S. Stephens, N. G. Tassi, D. B. Chase, and J. F. Rabolt, Macromolecules, 37, 573 (2004).

11. H. Dong, V. Nyame, A. G. Macdiarmid, and W. E. Jones, J. Polym. Sci., Part B: Polym. Phys., 42, 3934 (2004).

12. R. Jaeger, M. M. Bergshoef, C. M. I. Batlle, H. Schonherr, and G. J. Vancso, Macromol. Symp., 127, 141 (1998).

13. H. Q. Liu and Y. L. Hsieh, J. Polym. Sci., Part B: Polym. Phys., 40, 2119 (2002).

14. W. K. Son, J. H. Youk, T. S. Lee, and W. H. Park, J. Polym. Sci., Part B: Polym. Phys., 42, 5 (2004).

15. Y. L. Hsieh, Text. Res. J., 65, 297 (1995).

16. M. G. McKee, G. L. Wilkes, R. H. Colby, and T. E. Long, Macromolecules, 37, 1760 (2004).

17. A. Koski, K. Yim, and S. Shivkumar, Mater. Lett., 58, 493 (2004).

18. X. H. Zong, K. Kim, D. F. Fang, S. F. Ran, B. S. Hsiao, and B. Chu, Polymer, 43, 4403 (2002).

19. J. M. Deitzel, J. Kleinmeyer, D. Harris, and N. C. Beck Tan, Polymer, 42, 261 (2001).

20. J. M. Deitzel, W. Kosik, S. H. McKnight, N. C. B. Tan, J. M. DeSimone, and S. Crette, Polymer, 43, 1025 (2002).

21. H. Q. Liu and Y. L. Hsieh, Macromol. Rapid Commun., 27, 142 (2006). 